\title{
Reproducibility and Clinical Relevance of the Ocular Response Analyzer in Nonoperated Eyes: Corneal Biomechanical and Tonometric Implications
}

\author{
Javier Moreno-Montañés, ${ }^{1}$ Miguel J. Maldonado, ${ }^{1}$ Noelia García, ${ }^{1}$ Loreto Mendiluce, ${ }^{1}$ \\ Pio J. García-Gómez, ${ }^{1}$ and María Seguí-Gómez ${ }^{2,3}$
}

Purpose. To assess the reproducibility of the ocular response analyzer (ORA) in nonoperated eyes and the impact of corneal biomechanical properties on intraocular pressure (IOP) measurements in normal and glaucomatous eyes.

Methods. In the reliability study, two independent examiners obtained repeated ORA measurements in 30 eyes. In the clinical study, the examiners analyzed ORA and IOP-Goldmann values from 220 normal and 42 glaucomatous eyes. In both studies, Goldmann-correlated IOP measurement (IOP-ORAg), corneal-compensated IOP (IOP-ORAc), corneal hysteresis $(\mathrm{CH})$, and corneal resistance factor (CRF) were evaluated. IOP differences of $3 \mathrm{~mm} \mathrm{Hg}$ or greater between the IOP-ORAc and IOP-ORAg were considered outcome significant.

RESults. Intraexaminer intraclass correlation coefficients and interexaminer concordance correlation coefficients ranged from 0.78 to 0.93 and from 0.81 to 0.93 , respectively, for all parameters. $\mathrm{CH}$ reproducibility was highest, and the IOP-ORAg readings were lowest. The median IOP was $16 \mathrm{~mm} \mathrm{Hg}$ with the Goldmann tonometer, $14.5 \mathrm{~mm} \mathrm{Hg}$ with IOP-ORAg $(P<$ $0.001)$, and $15.7 \mathrm{~mm} \mathrm{Hg}$ with IOP-ORAc $(P<0.001)$. Outcome-significant results were found in 77 eyes (29.38\%). The IOP-ORAc, $\mathrm{CH}$, and CRF were correlated with age $(r=0.22$, $P=0.001 ; r=-0.23, P=0.001 ; r=-0.14, P=0.02$, respectively), but not the IOP-ORAg or IOP-Goldmann.

Concuusions. The ORA provides reproducible corneal biomechanical and IOP measurements in nonoperated eyes. Considering the effect of ORA, corneal biomechanical metrics produces an outcome-significant IOP adjustment in at least one quarter of glaucomatous and normal eyes undergoing noncontact tonometry. Corneal viscoelasticity $(\mathrm{CH})$ and resistance (CRF) appear to decrease minimally with increasing age in healthy adults. (Invest Ophthalmol Vis Sci. 2008;49:968-974) DOI: $10.1167 /$ iovs.07-0280

Thtraocular pressure (IOP) elevation is most commonly associated with glaucoma. ${ }^{1}$ Although analyzing the anatomic structure and visual function are of pivotal importance, ${ }^{2,3}$ ac-

From the ${ }^{1}$ Department of Ophthalmology, Clínica Universitaria, Universidad de Navarra, Pamplona, Spain; ${ }^{2}$ Department of Preventive Medicine and Salud Pública, Facultad de Medicina, Universidad de Navarra, Pamplona, Spain; and ${ }^{3}$ Health Policy and Management, Johns Hopkins University, Bloomberg School of Public Health, Baltimore, Maryland.

Submitted for publication March 7, 2007; revised July 17 and October 4, 2007; accepted January 18, 2008.

Disclosure: J. Moreno-Montañés, None; M.J. Maldonado, None; N. García, None; L. Mendiluce, None; P.J. García-Gómez None; M. Seguí-Gómez, None

The publication costs of this article were defrayed in part by page charge payment. This article must therefore be marked "advertisement" in accordance with 18 U.S.C. $\$ 1734$ solely to indicate this fact

Corresponding author: Javier Moreno-Montañés, Department of Ophthalmology, Clínica Universitaria, Universidad de Navarra, Apartado 4290, 31080 Pamplona, Spain; jmoreno@unav.es. curately measuring IOP remains challenging. ${ }^{4,5}$ The Goldmann tonometer (GT) is the gold standard. However, some corneal factors can affect the accuracy of the GT, such as corneal thickness, corneal curvature, edematous and scarred corneas, keratoconus, and corneal rigidity. ${ }^{6-10}$

A new noncontact tonometer (NCT; Ocular Response Analyzer [ORA]; Reichert, Delpew, NY) uses a rapid air impulse and an advanced electro-optical system to record two applanation pressures (Fig. 1) during corneal movements in and out. ${ }^{11}$ However, the cornea resists the dynamic air puff, causing delays in the inward and outward movement, resulting in two pressure values, the average of which is the Goldmann-correlated IOP measurement (IOP-ORAg). ${ }^{11}$ Corneal hysteresis $(\mathrm{CH})$ is a new measurement of corneal tissue properties reflecting the tissue capacity to absorb and dissipate energy. ${ }^{11} \mathrm{CH}$ may, therefore, have a prominent role in obtaining an IOP estimate of the true IOP with fewer corneal artifacts. Furthermore, $\mathrm{CH}$ may provide new information about biomechanical corneal properties useful for indicating keratorefractive surgery and planning retreatment to avoid iatrogenic keratectasia. ${ }^{12-15} \mathrm{CH}$ also provides a basis for two new parameters, corneal-compensated IOP (IOP-ORAc), which is mathematically derived from $\mathrm{CH}$ and is intended to produce improved IOP estimates-an assumption that should be confirmed by manometric studiesand corneal resistance factor (CRF), which appears to indicate corneal "resistance" (Luce DA, personal communication, 2005). Although $\mathrm{CH}$ may reflect mostly corneal viscosity, CRF (defined as a linear function of the inward and outward applanation pressures) may predominantly relate to the elastic properties of the cornea. ${ }^{16}$

$\mathrm{CH}$, which does not vary diurnally, ${ }^{17,18}$ decreases in glaucomatous eyes ${ }^{11,19}$ and may have an implication in glaucoma damage $^{20}$ that only longitudinal studies will demonstrate. However, there are possible systematic and random possible sources of error with any tonometer. ${ }^{21}$ Whereas the former are adjustable, ${ }^{22}$ the latter are inherent in instrument design and quality, can only be assessed by repeated measurements on the same patient, and are not adjustable. ${ }^{21}$ The ORA has a varying systematic error compared with the GT, depending on the ORA prototype $e^{22,23}$ or the production unit tested, ${ }^{16,19}$ that can be further calibrated. ${ }^{22}$ To our knowledge, no study has analyzed ORA repeatability for IOP estimations and biomechanical parameters, a need that other authors ${ }^{22}$ share with us.

The aims of the present study were to evaluate the precision of the ORA IOP and biomechanical corneal measurements by assessing intraobserver and interobserver reproducibility, evaluating the effects of the ORA corneal biomechanical properties on IOP adjustment by NCT in nonoperated eyes, and assessing a possible relationship between ORA parameters (compared with GT reading) and age in a healthy population.

\section{Materials ANd Methods}

A prospective, cross-sectional study was performed to evaluate IOP measurements using the ORA in nonoperated eyes. Informed consent 
Figure 1. Profiles corresponding to an ORA measurement of IOP and corneal biomechanical properties.

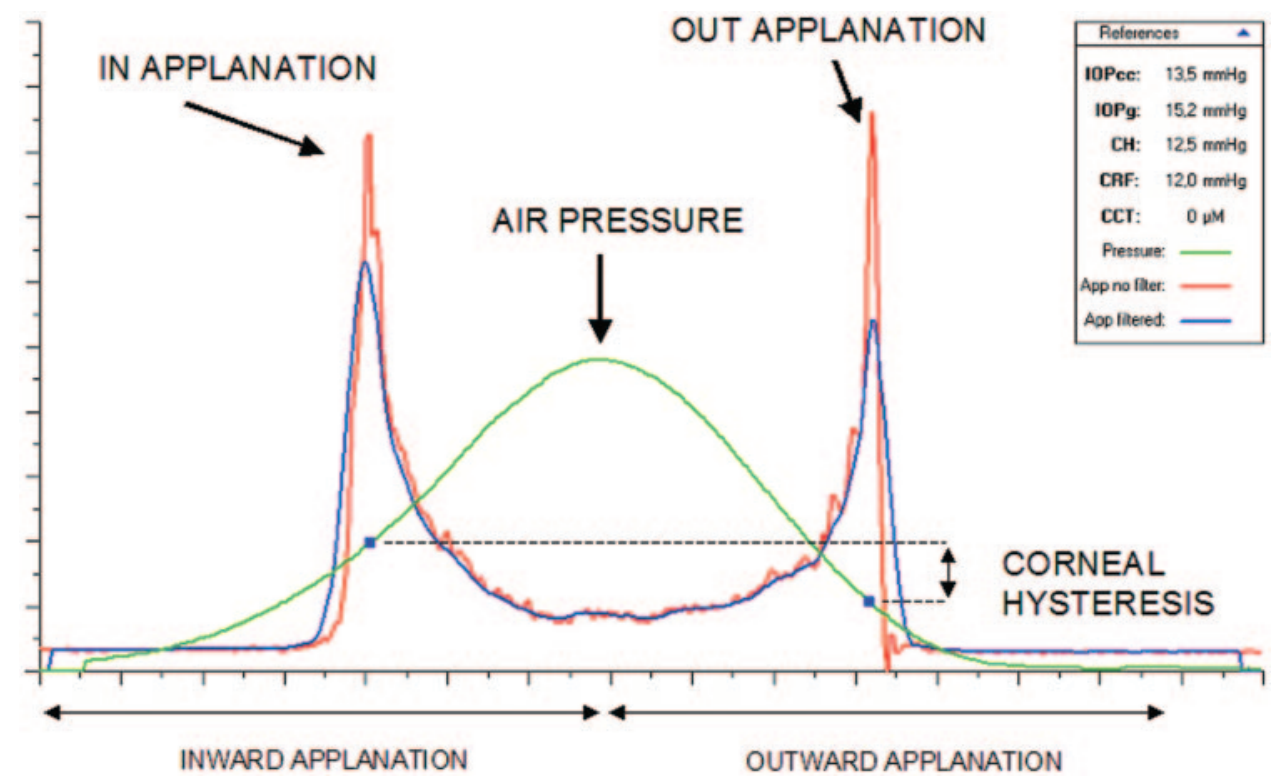

we have previously demonstrated that after three repeated air-puffs, IOP readings do not decrease noticeably. ${ }^{28}$

To evaluate the effect of the ORA corneal biomechanical metrics on NCT values (IOP-ORAc), measurement-significant adjustments (IOP-ORAc minus IOP-ORAg) were defined as IOP corrections of $\pm 1.5 \mathrm{~mm} \mathrm{Hg}$ or greater. ${ }^{29}$ Similarly, any ORA biomechanically derived IOP adjustments of $\pm 3.0 \mathrm{~mm} \mathrm{Hg}$ were designated as outcomessignificant. ${ }^{29}$

All analyses were performed using the SPSS program (version 13.0 for Windows; SPSS Inc., Chicago, IL) and the Stata program (version 9.0 for Windows; Statcorp LP, College Station, TX). Significance was determined by the Mann-Whitney $U$ nonparametric test, and data were expressed as medians and $25 \%$ and $75 \%$ interquartile ranges (IRs) because the values were found to be nonnormally distributed. The association between two variables was tested using the Spearman correlation coefficient given the nonnormal distribution of at least one variable. The significance level was set at $P<0.05$, by a two-tailed test. Agreement between IOP measurements was evaluated as described by Bland and Altman. ${ }^{21}$

To assess intraoperator repeatability, we calculated the withinsubject SD $\left(s_{w}\right)$ of two consecutive measurements in each eye by one examiner. ${ }^{30}$ Precision (repeatability coefficient) was defined as \pm 1.96 $s_{w}{ }^{30}$ The difference between a subject's measurement and the true value from a statistical standpoint was expected to be $\leq 1.96 s_{w}$ for $95 \%$ of the observations. ${ }^{12}$ We computed the "repeatability" (2.77. $s_{w}$ ), which is another useful way of presenting measurement error $^{30}$ and which represents the value below which we expected $95 \%$ of the absolute differences between two measurements to lie. ${ }^{30,31}$ We also calculated the intrasession reliability of the measurement method with the intraclass correlation coefficient (ICC). ${ }^{21}$

To assess interoperator reproducibility, a Bland-Altman plot showed the difference between both examiners' readings against the average of the two. ${ }^{21}$ Provided that the differences were normally distributed and no association between the measurement and the difference was shown, each 95\% limit of agreement (LoA) was calculated as the average difference in measurements from the two examiners $\pm 1.96 \mathrm{SD}$ (SD); lower values indicated higher interoperator repeatability. ${ }^{31}$ The paired $t$-test also established whether there was a significant systematic bias between measurements from different examiners. The interoperator reliability of the measurement method was calculated with the concordance correlation coefficient (CCC) ${ }^{32}$ 
TABLE 1. ORA Intraexaminer Repeatability: Within-Subject Standard Deviation $\left(s_{w}\right)$, Precision $\left(1.96 s_{w}\right)$, Repeatability $\left(2.77 s_{w}\right)$ Scores, and Reliability (ICC)

\begin{tabular}{lcccr}
\hline \multicolumn{1}{c}{ ORA Parameter } & $\boldsymbol{s}_{\boldsymbol{w}}(\mathbf{m m} \mathbf{H g})$ & Precision $(\mathbf{m m ~ H g})$ & Repeatability (mm Hg) & Reliability (95\% CI) \\
\hline Goldmann-correlated IOP & 3.333 & 6.53 & 9.23 & $0.93(0.87-0.95)$ \\
Corneal-compensated IOP & 2.384 & 4.67 & 6.60 & $0.78(0.48-0.89)$ \\
Corneal resistance factor & 1.946 & 3.81 & 5.39 & $0.93(0.84-0.96)$ \\
Corneal hysteresis & 1.454 & 2.85 & 4.03 & $0.84(0.67-0.92)$ \\
\hline
\end{tabular}

\section{Results}

\section{Reproducibility Study}

The intraexaminer within-subject SDs ranged from $1.45 \mathrm{~mm} \mathrm{Hg}$ for $\mathrm{CH}$ to $3.33 \mathrm{~mm} \mathrm{Hg}$ for IOP-ORAg (Table 1). Precision ranged from $2.85 \mathrm{~mm} \mathrm{Hg}$ for $\mathrm{CH}$ to $6.53 \mathrm{~mm} \mathrm{Hg}$ for IOP-ORAg. Repeatability, which ranged from 4.03 to $9.23 \mathrm{~mm} \mathrm{Hg}$, was better for $\mathrm{CH}$ than for CRF and for IOP-ORAc than for IOPORAg. Intraexaminer reliability (ICC) ranged from 0.78 to 0.93 (good to excellent) for the ORA parameters and tended to be slightly better for ORA biomechanical metrics than for ORA IOP readings, though the difference was not significant because all $95 \%$ confidence intervals (CIs) overlapped.

Interexaminer reproducibility average differences and their corresponding 95\% LoA illustrated the closeness between examiners (Table 2, Figs. 2, 3). No significant difference in the mean value of each parameter was found between examiners; the narrow 95\% LoA indicated that measurements obtained by both examiners were interchangeable. CCC values and 95\% CIs confirmed this. For all ORA parameters, the CCCs were very high, ranging from 0.81 to 0.93 . All CIs excluded the null value of 0 , indicating their significance. The markers of corneal biomechanical properties showed a trend toward better CCC values than the ORA IOP measurements, but the difference did not reach statistical significance.

\section{Clinical Study}

Of the 262 eyes (median age, 69 years; IR, 55-75 years; range, 19-88 years) included in this segment, $42 \mathrm{had}$ a diagnosis of primary open-angle glaucoma (median age, 63 years; IR, 50-72 years); 220 were normal (median age, 69 years; IR, 55-76 years).

The median IOP in all eyes was $16 \mathrm{~mm} \mathrm{Hg}$ (IR, 14-18) using GT, $14.5 \mathrm{~mm} \mathrm{Hg}$ (IR, 12.7-17.3) with IOP-ORAg, and $15.7 \mathrm{~mm}$ $\mathrm{Hg}$ (IR, 13.22-18.7) with IOP-ORAc. The differences were significant between GT and IOP-ORAg $(P<0.001)$ and between GT and IOP-ORAc $(P<0.001)$.

The median difference in all eyes between IOP-ORAc and IOP-ORAg was $1.5 \mathrm{~mm} \mathrm{Hg}$ (IR, 0.7-3.0; $P=0.001$ ). This median difference did not differ significantly between normal and glaucomatous eyes $(1.5 \mathrm{~mm} \mathrm{Hg}$ [IR, 0.7-3.0] and $1.7 \mathrm{~mm}$ $\mathrm{Hg}$ [IR, 0.92-3.7], respectively; $P=0.34$ ). Figure 4 shows the corresponding scatter and Bland-Altman plots between IOPORAc and IOP-ORAg; each 95\% LoA was wide (-3.32-5.57 $\mathrm{mm} \mathrm{Hg}$ ), indicating these ORA parameters are not interchangeable.
In this series, 135 eyes (51.5\%) had at least a measurementsignificant adjustment in the NCT examination after the ORA markers of corneal biomechanical properties were considered. IOP-ORAg was lower than IOP-ORAc by $\geq 1.5 \mathrm{~mm} \mathrm{Hg}$ in 26 eyes (9.9\%) and higher than IOP-ORAc by $\geq 1.5 \mathrm{~mm} \mathrm{Hg}$ in 109 eyes (41.6\%). IOP-ORAg was lower than IOP-ORAc by $\geq 3 \mathrm{~mm}$ $\mathrm{Hg}$ in 9 eyes (3.4\%) and higher than IOP-ORAc by $\geq 3 \mathrm{~mm} \mathrm{Hg}$ in 68 eyes $(25.9 \%)$.

Twenty-two glaucomatous eyes (52.3\%) had at least a measurement-significant adjustment in their NCT examination after ORA corneal biomechanical metrics were considered. IOPORAg was lower than IOP-ORAc by $\geq 1.5 \mathrm{~mm} \mathrm{Hg}$ in 5 eyes (11.9\%) and higher than IOP-ORAc by $\geq 1.5 \mathrm{~mm} \mathrm{Hg}$ in 17 eyes (40.4\%). Outcomes-significant IOP changes were detected in 13 eyes (30.9\%). IOP-ORAg was lower than IOP-ORAc by $\geq 3$ $\mathrm{mm} \mathrm{Hg}$ in 2 eyes (4.76\%) and higher than IOP-ORAc by $\geq 3 \mathrm{~mm}$ $\mathrm{Hg}$ in 11 eyes (26.2\%).

One hundred thirteen normal eyes (51.3\%) had at least a measurement-significant adjustment in their NCT examination after ORA markers of corneal biomechanical properties were considered. IOP-ORAg was lower than IOP-ORAc by $\geq 1.5 \mathrm{~mm}$ $\mathrm{Hg}$ in 21 eyes (9.5\%) and higher than IOP-ORAc by $\geq 1.5 \mathrm{~mm}$ $\mathrm{Hg}$ in 92 eyes (41.8\%). Outcomes-significant IOP changes were detected in 64 eyes (29.1\%). IOP-ORAg was lower than IOPORAc by $\geq 3 \mathrm{~mm} \mathrm{Hg}$ in 7 eyes (3.2\%) and higher than IOPORAc by $\geq 3 \mathrm{~mm} \mathrm{Hg}$ in 57 eyes (25.9\%).

Table 3 shows a comparison of the IOP values, CRF, and $\mathrm{CH}$ in normal and glaucomatous eyes. Only $\mathrm{CH}$ was not significantly different between the groups.

In the entire series, IOP-ORAc was weakly positively correlated with age $\left(r_{s}=0.18, P=0.005\right)$, whereas IOP-ORAg and GT were not $\left(r_{s}=0.03, P=0.59 ; r_{s}=-0.03, P=0.67\right.$, respectively). $\mathrm{CH}$ and $\mathrm{CRF}$ were inversely correlated with age ( $r_{s}=-0.26, P<0.001 ; r_{s}=-0.19, P=0.002$, respectively).

In glaucomatous eyes, IOP-ORAc was positively correlated with age $\left(r_{s}=0.34, P=0.02\right)$, whereas IOP-ORAg and GT were not $\left(r_{s}=0.22, P=0.16 ; r_{s}=0.13, P=0.42\right.$, respectively). $\mathrm{CH}$ but not CRF was inversely correlated with age $\left(r_{s}=\right.$ $-0.33, P=0.03 ; r_{s}=-0.12, P=0.44$, respectively).

In normal eyes, IOP-ORAc was weakly positively correlated with age $\left(r_{s}=0.22, P=0.001\right)$, whereas IOP-ORAg and GT were not $\left(r_{s}=0.07, P=0.29 ; r_{s}=0.07, P=0.92\right.$, respectively). $\mathrm{CH}$ and $\mathrm{CRF}$ were inversely correlated with age $\left(r_{s}=\right.$ $-0.26, P<0.001 ; r_{s}=-0.18, P=0.006$, respectively).

TABLE 2. ORA Interexaminer Reproducibility: Mean Difference between Examiners, 95\% LoA, and CCC

\begin{tabular}{lccr}
\hline \multicolumn{1}{c}{ ORA Parameter } & Average Difference (mm Hg) & 95\% LoA (mm Hg) & CCC (95\% CI) \\
\hline Goldmann-correlated IOP & 0.05 & $-2.87,2.97$ & $0.89(0.82-0.97)$ \\
Corneal-compensated IOP & 0.05 & $-2.68,2.79$ & $0.81(0.68-0.94)$ \\
Corneal resistance factor & -0.023 & $-1.38,1.34$ & $0.93(0.89-0.98)$ \\
Corneal hysteresis & 0.06 & $-1.07,1.19$ & $0.92(0.87-0.98)$ \\
\hline
\end{tabular}




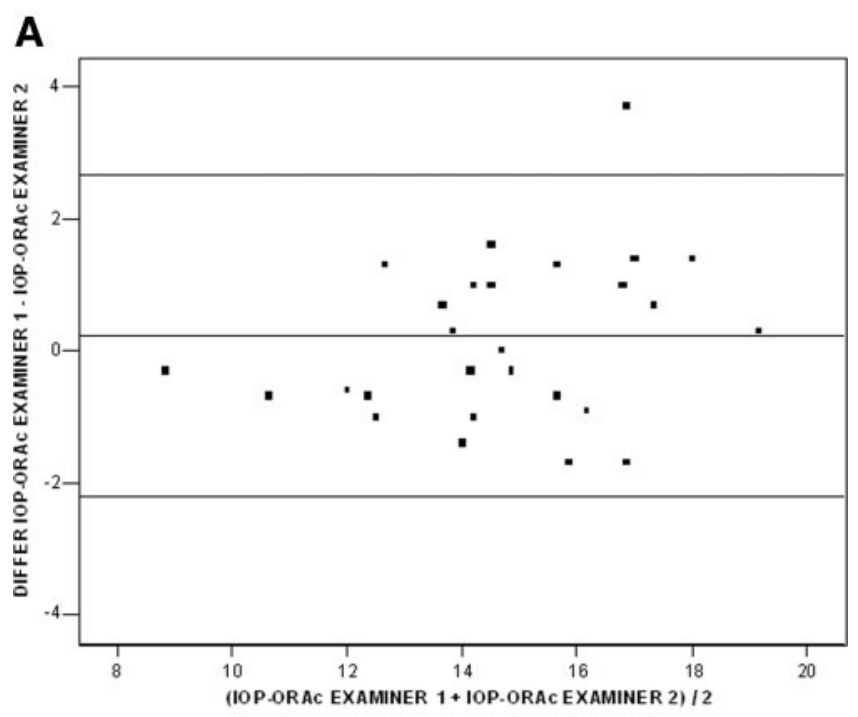

B

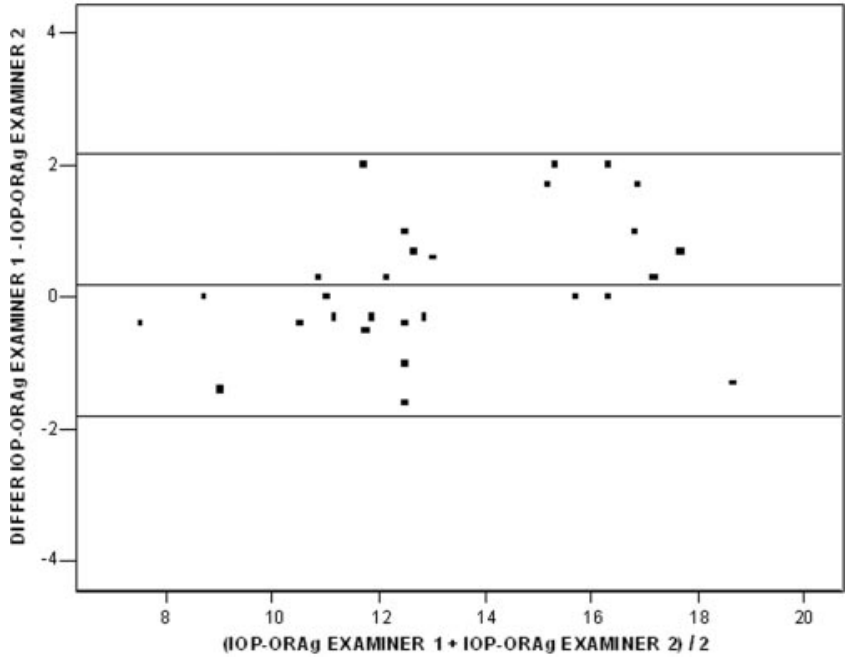

FiguRE 2. Bland-Altman plot showing the agreement between examiners 1 and 2 in measuring (A) IOP-ORAc in $\mathrm{mm} \mathrm{Hg}$ and (B) IOP-ORAg in $\mathrm{mm} \mathrm{Hg}$ (30 healthy eyes; median age, 29 years; $25 \%$ and $75 \%$ interquartile ranges, $23.75-33$ years).

\section{Discussion}

We obtained excellent intraexaminer reliability scores $(>0.9)$ for Goldmann-correlated IOP and CRF (Table 1) and found clinically useful reliability estimates $(>0.7)^{33}$ in the IOP-ORAc and $\mathrm{CH}$. These values are similar to those for other tonometers and are considered by previous authors as clinically adequate. $^{33}$ The ICCs for rebound tonometry ${ }^{34}$ were $0.82,0.73$, and 0.87 , respectively, for the first, second, and third examiners, and the ICCs for the GT and tonometer (Tono-Pen; Reichert) were 0.97 and 0.95 , respectively. ${ }^{35}$ Although no significant difference was found, ORA corneal biomechanical metrics showed a trend toward slightly better than ORA IOP readings, perhaps because corneal tissue biomechanical properties are fairly constant, whereas the IOP changes with the cardiac cycle, and NCT measures the IOP within 1 to $3 \mathrm{~ms}$, making the ocular pulse a crucial source of variability. ${ }^{36} \mathrm{Ko}-$ techa et al. ${ }^{22}$ found that the coefficient of variation of ORA IOP measurements was four to five times greater than that of GT IOP measurements. However, they calculated coefficients of variation for $\mathrm{CH}$ and $\mathrm{CRF}$ nearly twice as high as those for
IOP-ORAc. Differences between the studies might have occurred because our ORA was a commercially available unit, whereas theirs was a prototype, ${ }^{22}$ and because we averaged three repeated ORA readings and they did not, with averaging favoring more corneal biomechanical metrics than ORA IOP readings. The ability to yield reliable corneal biomechanical metrics is an outstanding feature of the ORA when determining candidates for keratorefractive surgery or for retreatments. ${ }^{13-16}$ Given the growing concern about iatrogenic keratectasia, ${ }^{12-15}$ ORA biomechanical parameters may contribute significantly to preoperative screening of patients who are not candidates for keratorefractive surgery or who seek surgical alternatives because of a biomechanically compromised cornea. ${ }^{12,16}$

Table 1 also shows the $s_{w}$ for each ORA parameter. The precision results corroborated our ICC findings. These three estimates differentiate between statistically and clinically significant changes when different datasets obtained with the same ORA unit are compared.

When the ORA measurements recorded by two examiners were compared, the mean differences were not significantly

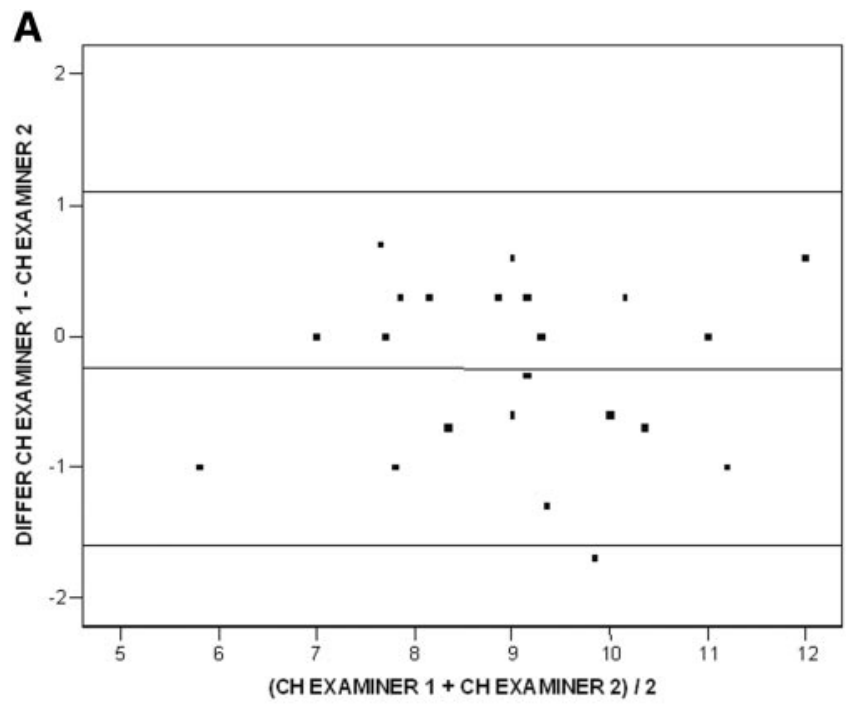

B

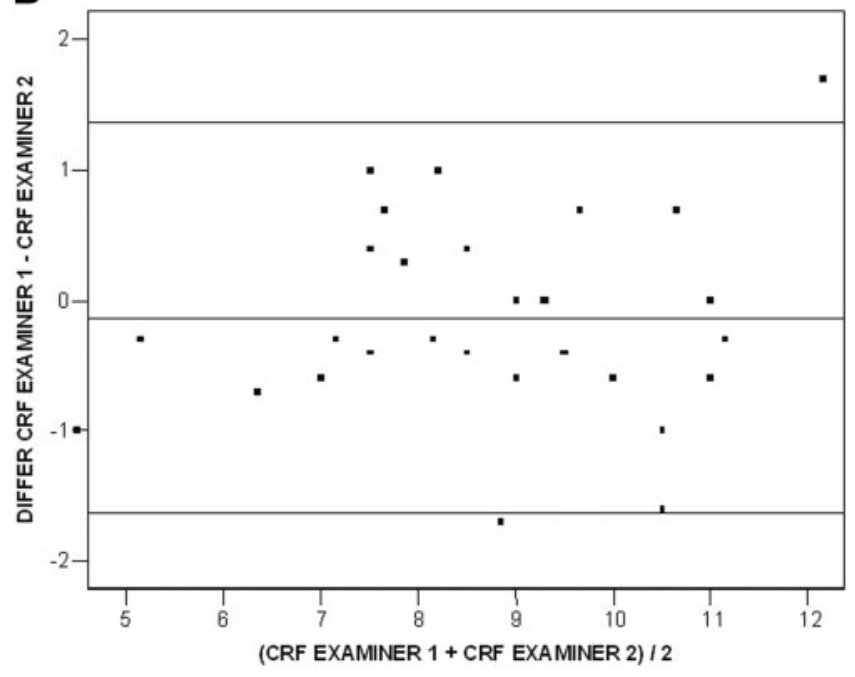

FIGURE 3. Bland-Altman plot showing agreement between examiners 1 and 2 in measuring (A) ORA CH ( $\mathrm{mm} \mathrm{Hg}$ ) and (B) ORA CRF in $\mathrm{mm}$ $\mathrm{Hg}$ (30 normal eyes; median age, 29 years; $25 \%$ and $75 \%$ interquartile ranges, $23.75-33$ years). 


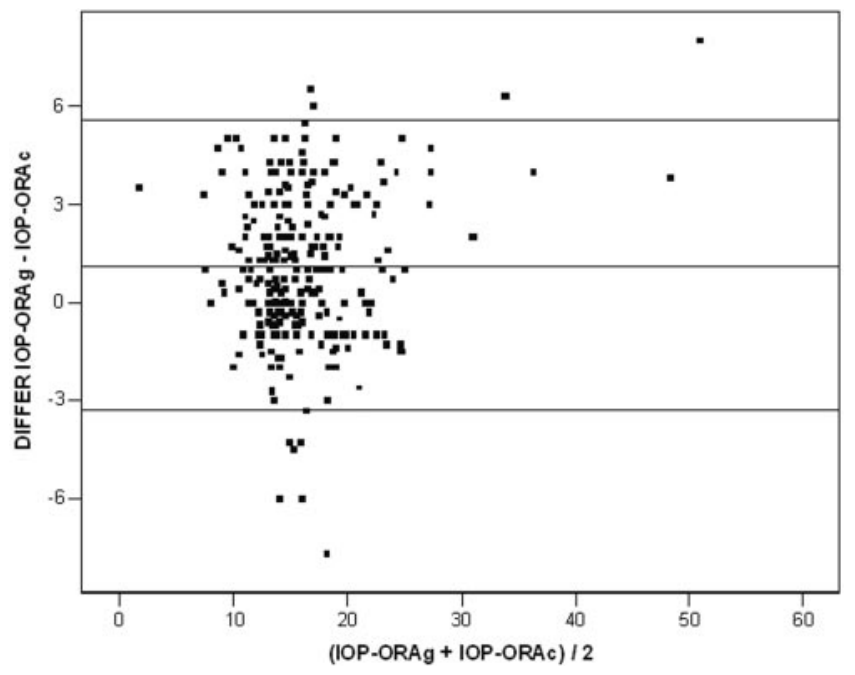

FIGURE 4. Corresponding scatter and Bland-Altman plots between IOP-ORAc ( $\mathrm{mm} \mathrm{Hg}$ ) and IOP-ORAg in $\mathrm{mm} \mathrm{Hg}$ (220 normal and 42 glaucomatous eyes; median age, 69 years; $25 \%$ and $75 \%$ interquartile ranges, 55-75 years).

different from 0 (Table 2). Not surprisingly, no difference in ORA measures was found, indicating that whatever the source of the variability, the interobserver variability was random. The 95\% LoA (Table 2) provided useful guidelines for the variability expected using the ORA by two examiners. In fact, the amplitude of the $95 \%$ LoA was narrow, indicating that ORA readings obtained by both examiners were interchangeable. These data and the CCCs indicated that the reliability of ORA IOP and corneal biomechanical parameters obtained by different examiners were good to excellent: CCCs $>0.81$ indicated almost perfect agreement, ${ }^{32,37}$ as with the four ORA parameters. These findings also indicated that no examiner bias affected the results. These reproducibility data were similar to those of other tonometers: the ICC of the rebound tonometer was $0.82,{ }^{34}$ with similar figures reported for other tonometers. ${ }^{38-40}$ Overall, our results suggested that ORA reproducibility was similar to or better than that of other tonometers. $34,35,38-41$

Although it was not a primary aim of the present study to establish a correlation between GT to IOP-ORA measurements, we also studied the GT to determine whether IOP-ORAg was similar to GT and whether ORA parameters and GT are influenced by age to the same extent in the same group of patients. We found significant systematic differences between the IOPORAc and IOP-ORAg provided by the ORA and the IOP-GT readings; the latter provided higher readings. Such differences cannot be attributed to bias related to the order of IOP measurements because repeated measures lead to a tonometric effect that reduces ${ }^{24,42}$ the IOP and because topical anesthetics may cause corneal drying and an associated drop in IOP,${ }^{26,27}$ in contrast to the current results. The systematic difference be- tween our IOP-ORAg and GT, which was not as large as reported after an ORA prototype was analyzed, ${ }^{23}$ agrees with the findings of others ${ }^{16,19}$ and probably represents a modest calibration error that can be further adjusted. ${ }^{22}$ Nevertheless, NCTs are useful for population surveys; no corneal contact or topical anesthesia are needed, which eliminates corneal disturbance, ${ }^{43}$ and the instruments lower the risk for transmitting communicable diseases. ${ }^{44}$ However, great variations occur with NCTs, ${ }^{45}$ partially because of the cardiac pulse. ${ }^{25,36,46-49}$ When comparing three NCTs with the GT, we found better sensitivity and positive predictive values for detecting IOP $>20$ $\mathrm{mm} \mathrm{Hg}$ than in the present study using IOP-ORAc and IOPORAg. ${ }^{50}$

The median IOP difference between IOP-ORAc and IOPORAg was $1.5 \mathrm{~mm} \mathrm{Hg}$, which was not significantly different from that comparing normal with glaucomatous eyes and was similar to that of other studies. ${ }^{23}$ Bland-Altman analysis confirmed that the parameters are not interchangeable and that they represent two different estimations. We found that considering the biomechanical properties measured by the ORA resulted in a considerable modification ( $\geq 3 \mathrm{~mm} \mathrm{Hg}$ ) in $29 \%$ of the IOP measurements, a higher percentage than the $20 \%$ of the IOP measurements Shih et al. found considering the effect of central corneal thickness (CCT), ${ }^{29}$ which suggests that the ORA integrates more complex and complete biomechanical properties than CCT does on its own. This $29 \%$ was essentially uniform across normal and glaucomatous eyes, and 25\% to $26 \%$ corresponded to higher IOP-ORAg readings than IOP-ORAc readings. Thus, in nonoperated eyes, IOP-ORAc measurements showed that nearly $25 \%$ of persons had a notably lower reading than that obtained with a conventional NCT and that another $3 \%$ to $4 \%$ had markedly higher IOP measurements than those obtained with a conventional NCT. These adjustments may lead to, respectively, elimination of unneeded diagnostic and therapeutic actions and early diagnosis and timely treatment of truly glaucomatous eyes. ${ }^{29,51-53}$

In our study, ORA corneal biomechanical parameters showed that the median $\mathrm{CH}$ was $9.3 \mathrm{~mm} \mathrm{Hg}$ in glaucomatous and normal eyes compared with $9.6 \mathrm{~mm} \mathrm{Hg}$ reported previously in normal eyes. ${ }^{11}$ Herndon $^{4}$ and Luce $^{11}$ reported that $\mathrm{CH}$ is independent of IOP. Laiquzzaman et al. ${ }^{17}$ found no significant relationship between $\mathrm{CH}$ and IOP. Interestingly, Congdon et $\mathrm{al}^{20}$ found that lower $\mathrm{CH}$ is associated with visual field damage in glaucomatous eyes. CCT and $\mathrm{CH}$ may constitute pressure-independent risk factors for glaucoma, perhaps related to eye wall composition. ${ }^{20}$ Furthermore, $\mathrm{CH}$ does not vary diurnally, ${ }^{17,18}$ in contrast to $\mathrm{IOP}^{17,18}$ and corneal thickness. ${ }^{18}$

There is a likely effect of age on physical corneal properties. $^{22,54,55}$ We analyzed 220 healthy adults at an interquartile age range of 55 to 76 years, when most glaucoma diagnoses are made. ${ }^{56,57}$ In contrast to that observed for a comparably narrower age range in a pediatric population, ${ }^{19} \mathrm{CH}$ and $\mathrm{CRF}$ decreased in normal eyes with increasing age, which corroborates analyses from a mixed population of normal and glaucomatous eyes. ${ }^{22}$ Such results can be explained because the

TABLE 3. Comparison of Evaluated Data between Normal and Glaucomatous Eyes

\begin{tabular}{|c|c|c|c|c|c|c|}
\hline Values & Number & $\begin{array}{l}\text { IOP } \\
\text { Goldmann }\end{array}$ & $\begin{array}{c}\text { Goldmann-Correlated } \\
\text { IOP in ORA }\end{array}$ & $\begin{array}{c}\text { Corneal-Compensated } \\
\text { IOP in ORA }\end{array}$ & $\begin{array}{c}\text { Corneal } \\
\text { Resistance }\end{array}$ & $\begin{array}{c}\text { Corneal } \\
\text { Hysteresis }\end{array}$ \\
\hline Normal & 220 & $15(13-17)$ & $14(12.3-16.7)$ & $15(13-18)$ & $9.3(8-10.5)$ & $9.3(8-10.65)$ \\
\hline Glaucoma & 42 & $18(14.25-20)$ & $17.3(14.45-22.07)$ & $18.3(15.45-21.4)$ & $10.3(8.9-12)$ & $9.3(7.22-10.77)$ \\
\hline$P^{*}$ & & $<0.001$ & $<0.001$ & $<0.001$ & 0.006 & 0.83 \\
\hline
\end{tabular}

Data are expressed as median values in $\mathrm{mm} \mathrm{Hg}$ ( $75 \%$ interquartile range).

* Mann-Whitney nonparametric test. 
aging cornea increases in rigidity and decreases in viscoelasticity with time, ${ }^{22,54,55}$ which is consistent with the inverse correlation we found between $\mathrm{CH}$ and age but not with the weak negative correlation between CRF and age. However, in glaucomatous eyes, the CRF did not correlate with age compared with $\mathrm{CH}$, possibly because although corneal rigidity should be expected to increase with age, likely because of additional cross-linking, the impact of increasing IOP on CRF is unknown.

Interestingly, in normal and glaucomatous eyes, IOP-ORAc but not IOP-ORAg or GT, readings correlated significantly with increasing age. Further longitudinal studies may confirm this preliminary association.

This study had limitations. The number of patients with glaucoma was relatively small, but statistical differences in GT, IOP-ORAc, and IOP-ORAg were found between eyes with and without glaucoma. Nevertheless, the present study was the largest independent clinical study evaluating ORA to date. In addition, no measurements of corneal thickness were considered; however, the effect of corneal thickness was included in other corneal parameters, such as CRF, and the relationship between CCT and ORA parameters has been studied extensively. ${ }^{22,23,58,59}$ Finally, it is difficult to know whether the definition of measurement-significant $(\geq 1.5 \mathrm{~mm} \mathrm{Hg})$ and outcomes-significant $(\geq 3.0 \mathrm{~mm} \mathrm{Hg}$ ) are useful in IOP adjustments, but these cutoff values were defined previously. ${ }^{29}$ Despite limitations, this study was the first to evaluate the reproducibility of a production ORA unit and the practical effect of corneal biomechanical parameters on IOP measurements in nonoperated eyes. We believe the current report is a valuable contribution to the assessment of IOP measurements with a new NCT and noninvasive markers of corneal biomechanical properties.

Our results showed overall good intraexaminer and interexaminer reproducibility for ORA measurements in nonoperated eyes, with the corneal biomechanical metrics showing a trend toward the performance of slightly better than the IOP estimates. Consequently, the ability to provide reliable readings heralds a relevant role for the ORA in diagnosing glaucoma ${ }^{4,22}$ and in assessing cornea patients or candidates for corneal-weakening surgeries. ${ }^{12-16}$ This study also showed that accounting for the ORA corneal biomechanical metrics in the IOP measurement would associate an outcomes-significant adjustment of the NCT reading in 29\% of the tested eyes, which has overt screening and cost-related implications. ${ }^{52,60}$ Finally, patients with both normal and glaucomatous eyes have significant associations between increasing age and decreasing $\mathrm{CH}$ and CRF and increasing IOP-ORAc but no association with other IOP estimates. Future studies should address whether IOP-ORAc is a better estimate of the true IOP than other existing tonometry alternatives in nonoperated eyes. The risk for glaucoma increases with age ${ }^{56,57}$ and elevated IOP is a risk factor for glaucoma ${ }^{56,57}$ and the one that constitutes the main therapeutic target in this prevalent eye disease. ${ }^{4,56,57}$

\section{References}

1. Weih LM, Mukesh BN, McCarty CA, Taylor HR. Association of demographic, familial, medical, and ocular factors with intraocular pressure. Arch Ophthalmol. 2001;119:875-880.

2. Anton A, Moreno-Montañés J, Blazquez F, Alvarez A, Martin B, Molina B. Usefulness of optical coherence tomography parameters of the optic disc and the retinal nerve fiber layer to differentiate glaucomatous, ocular hypertensive, and normal eyes. J Glaucoma. 2007; 16:1-8.

3. Moreno-Montañés J, Alvarez-Vidal A, Sainz Gomez C, Rodriguez Conde R. Capa de fibras nerviosas en ojos glaucomatosos: estudio realizado mediante OCT y su comparación con el campo visual. Arch Soc Esp Oftalmol. 2002;77:435- 441.
4. Herndon LW. Measuring intraocular pressure-adjustments for corneal thickness and new technologies. Curr Opin Ophthalmol. 2006; 17:115-119.

5. Moreno-Montañés J, Teutsch P, Rodriguez-Conde R, Corcostegui I. Factores relacionados con la asimetría tensional en el síndrome pseudoexfoliativo. Arch Soc Esp Oftalmol. 2002;77:309-313.

6. Damji KF, Muni RH, Munger RM. Influence of corneal variables on accuracy of intraocular pressure measurement. J Glaucoma. 2003; 12:69-80.

7. Kohlhaas M, Boehm AG, Spoerl E, Pürsten A, Grein HJ, Pillunat LE. Effect of central corneal thickness, corneal curvature, and axial length on applanation tonometry. Arch Ophthalmol. 2006;124: 471-476.

8. Whitacre MM, Stein R. Sources of error with use of Goldmann-type tonometers. Surv Ophthalmol. 1993;38:1-30.

9. Brooks AM, Robertson IF, Mahoney AM. Ocular rigidity and intraocular pressure in keratoconus. Aust J Ophthalmol. 1984;12: 317-324.

10. Whitacre MM, Stein RA, Hassanein K. The effect of corneal thickness on applanation tonometry. Am J Ophthalmol. 1993;115:592596.

11. Luce DA. Determining in-vivo biomechanical properties of the cornea with an ocular response analyzer. J Cataract Refract Surg. 2005;31:156-162.

12. Randleman JB. Post-laser in-situ keratomileusis ectasia: current understanding and future directions. Curr Opin Ophthalmol. 2006; $17: 406-412$.

13. Maldonado MJ. Undersurface ablation of the flap for laser in situ keratomileusis retreatment. Ophthalmology. 2002;109:14531464 .

14. Maldonado MJ, Nieto JC, Diez-Cuenca M, Pinero DP. Posterior corneal curvature changes after undersurface ablation of the flap and in-the-bed LASIK retreatment. Ophthalmology. 2006;113: $1125-1133$.

15. Maldonado MJ, Juberias JR, Rodriguez-Conde R. Corneal flap thickness and tissue laser ablation in myopic LASIK. Ophthalmology. 2002;109:1042-1043.

16. Pepose JS, Feigenbaum SK; Qazi MA, Sanderson JP, Roberts CJ. Changes in corneal biomechanics and intraocular pressure following LASIK using static, dynamic, and noncontact tonometry. Am J Ophthalmol. 2007;143:39-47.

17. Laiquzzaman M, Bhojwani R, Cunliffe I, Shah S. Diurnal variation of ocular hysteresis in normal subjects: relevance in clinical context. Clin Exp Ophthalmol. 2006;34:114-118.

18. Kida T, Liu JH, Weinreb RN. Effect of 24-hour corneal biomechanical changes on intraocular pressure measurement. Invest Ophthalmol Vis Sci. 2006;47:4422-4426.

19. Kirwan C, O'Keefe M, Lanigan B. Corneal hysteresis and intraocular pressure measurement in children using the Reichert ocular response analyzer. Am J Ophthalmol. 2006;142:990-992.

20. Congdon NG, Broman AT, Bandeen-Roche K, Grover D, Quigley HA. Central corneal thickness and corneal hysteresis associated with glaucoma damage. Am J Ophthalmol. 2006;141:868-875.

21. Bland JM, Altman DG. Statistical methods for assessing agreement between two methods of clinical measurement. Lancet. 1986;1: 307-310.

22. Kotecha A, Elsheikh A, Roberts CR, Zhu H, Garway-Heath DF. Corneal thickness-and age-related biomechanical properties of the cornea measured with the ocular response analyzer. Invest $O p h$ thalmol Vis Sci. 2006;47:5337-5347.

23. Martinez-de-la-Casa JM, Garcia-Feijoo J, Fernandez-Vidal A, MendezHernandez C, Garcia-Sanchez J. Ocular response analyzer versus Goldmann applanation tonometry for intraocular pressure measurements. Invest Ophthalmol Vis Sci. 2006;47:4410 - 4414.

24. Kakau CET, Wilke K. On repeated tonometry. Acta Ophthalmol Scand. 1971;49:611-614.

25. Jorge J, González-Méijome JM, Díaz-Rey JA, Almeida JB, Ribeiro P, Parafita MA. Clinical performance of non-contact tonometry by Reichert AT550 in glaucomatous patients. Ophthalmic Physiol Opt. 2003;23:503-506.

26. Baudouin C, Gastaud P. Influence of topical anesthesia on tonometric values of intraocular pressure. Ophthalmologica. 1994; 208:309-313. 
27. Dayanir V, Sakarya R, Ozcura F, et al. Effect of corneal drying on central thickness. J Glaucoma. 2004;13:6-8.

28. Moreno-Montañés J, Aliseda D, Lajara J, Gómez E. Variaciones de la tensión ocular en la tonometría repetida de aire. Arch Soc Esp Oftal. 1995;69:135-140.

29. Shih CY, Graff Zivin JS, Trokel SL, Tsai JC. Clinical significance of central corneal thickness in the management of glaucoma. Arch Opbthalmol. 2004;122:1270-1275.

30. Bland JM, Altman DG. Measurement error. BMJ. 1996;313:744.

31. Bland M. An Introduction to Medical Statistics. 3rd ed. Oxford, UK: Oxford University Press; 2000;268-275.

32. Lin LI. A concordance correlation coefficient to evaluate reproducibility. Biometrics. 1989;45:255-268.

33. Shrout PE, Fleiss JL. Intraclass correlations: uses in assessing rater reliability. Psychol Bull. 1979;86:420 - 428.

34. Martinez-de-la-Casa JM, Garcia-Feijoo J, Castillo A, Garcia-Sanchez J. Reproducibility and clinical evaluation of rebound tonometry. Invest Opbthalmol Vis Sci. 2005;46:4578-4580.

35. Horowitz GS, Byles J, Lee J, D'Este C. Comparison of the Tono-Pen and Goldmann tonometer for measuring intraocular pressure in patients with glaucoma. Clin Exp Opbthalmol. 2004;32:584-589.

36. Shields MB. The non-contact tonometer: its value and limitations. Surv Ophthalmol. 1980;244:211-219.

37. Lin LI. A note on the concordance correlation coefficient. Biometrics. 2000;56:324-325.

38. Fernandes P, Diaz-Rey JA, Queiros A, et al. Comparison of the ICare rebound tonometer with the Goldmann tonometer in a normal population. Opbthalmic Physiol Opt. 2005;25:436-440.

39. Van der Jagt LH, Jansonius NM. Three portable tonometers, the TGDC-01, the ICARE and the Tonopen XL, compared with each other and with Goldmann applanation tonometry. Opbthalmic Pbysiol Opt. 2005;25:429-435.

40. Brusini P, Salvetat ML, Zeppieri M, Tosoni C, Parisi L. Comparison of ICare tonometer with Goldmann applanation tonometer in glaucoma patients. J Glaucoma. 2006;15:213-217.

41. Moreno-Montañés J, Sadaba LM, Heras H. Medición de presión intraocular con el tonómetro Proview ${ }^{\circledR}$. Arch Soc Esp Oftalmol. 2005;80:79-83.

42. Jorge J, Diaz-Rey JA, Gonzalez-Meijome JM, Almeida JB, Parafita MA. Clinical performance of the Reichert AT550: a new noncontact tonometer. Opbthalmic Physiol Opt. 2002;22:560-564.

43. Maldonado MJ. Corneal epithelial alterations resulting from use of chlorine-disinfected contact tonometer after myopic photorefractive keratectomy. Ophthalmology. 1998;105:1546-1549.

44. Maldonado MJ, Rodriguez-Galietero A, Cano-Parra J, Menezo JL, Diaz-LLopis M. Goldmann applanation tonometry using sterile disposable silicone tonometer shields. Ophthalmology. 1996;103: 815-821.

45. Cho P, Lui T. Comparison of the performance of the Nidek NT2000 noncontact tonometer with the Keeler Pulsair 2000 and the Goldmann applanation tonometer. Optom Vis Sci. 1997;74:51-58.
46. Nicastro NJ. Intraocular pressure-the cardiac connection. Ann Ophthalmol. 1991;23:366-372.

47. Kontiola A, Puska P. Measuring intraocular pressure with the Pulsair 3000 and Rebound tonometers in elderly patients without an anesthetic. Graefe's Arch Clin Exp Opbthalmol. 2004;242:3-7.

48. Sanchez-Tocino H, Bringas-Calvo R, Iglesias-Cortinas D. Estudio comparativo entre el neumotonómetro de no contacto Canon Tx-10 Y el tonómetro de Goldmann. Arch Soc Esp Oftalmol. 2005;80:643-649.

49. Tonnu PA, Ho T, Sharma K, White E, Bunce C, Garway-Heath D. A comparison of four methods of tonometry: method agreement and interobserver variability. Br J Ophthalmol. 2005;89:847-850.

50. Moreno-Montañés J, Gomez-Demmel E, Lajara-Blesa J, AlisedaPerez DM. Comparative study of three non-contact tonometers and the Goldmann tonometer. Opbthalmologica. 1994;208:115-118.

51. Jonas JB, Stroux A, Velten I, Juenemann A, Martus P, Budde WM. Central corneal thickness correlated with glaucoma damage and rate of progression. Invest Ophthalmol Vis Sci. 2005;46:12691274 .

52. Ventura AC, Böhnke M, Mojon DS. Central corneal thickness measurements in patients with normal tension glaucoma, primary open angle glaucoma, pseudoexfoliation glaucoma, or ocular hypertension. Br J Opbthalmol. 2001;85:792-795.

53. Brandt JD, Beiser JA, Gordon MO, Kass MA; Ocular Hypertension Treatment Study (OHTS) Group. Central corneal thickness and measured IOP response to topical ocular hypotensive medication in the Ocular Hypertension Treatment Study. Am J Opbthalmol. 2004; 138:717-722

54. Daxer, Misof K, Grabner B, Ettl A, Fratzl P. Collagen fibrils in the human corneal stroma: structure and aging. Invest Ophthalmol Vis Sci. 1998;39:644-648.

55. Malik NS, Moss SJ, Ahmed N, et al. Ageing of the human corneal stroma: structural and biochemical changes. Biochim Biophys Acta. 1992;11383:222-228

56. Le A, Mukesh BN, McCarty CA, Taylor HR. Risk factors associated with the incidence of open-angle glaucoma; the visual impairment project. Invest Ophthalmol Vis Sci. 2003;44:3783-3789.

57. Elolia R, Stokes J. Monograph series on aging-related diseases, XI: glaucoma. Cbronic Dis Can. 1998;19:157-169.

58. Shah S, Laiquzzaman M, Cunliffe I, Mantry S. The use of the Reichert ocular response analyser to establish the relationship between ocular hysteresis, corneal resistance factor and central cornea thickness in normal eyes. Cont Lens Anterior Eye. 2006; 29:257-262.

59. Medeiros FA, Weinreb RN. Evaluation of the influence of corneal biomechanical properties on intraocular pressure measurements using the ocular response analyser. J Glaucoma. 2006;15:364730 .

60. Rouland JF, Berdeaux G, Lafuma A. The economic burden of glaucoma and ocular hypertension: implications for patient management: a review. Drugs Aging. 2005;22:315-321. 